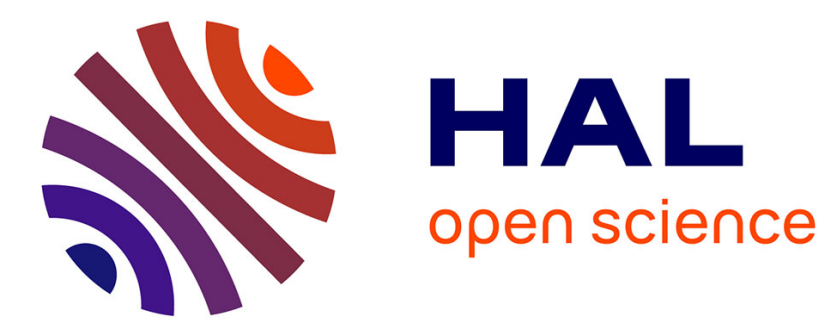

\title{
Systematic First-Principles Study of Binary Metal Hydrides
}

Natacha Bourgeois, Jean-Claude Crivello, Pierre Cenedese, Jean-Marc Joubert

\section{To cite this version:}

Natacha Bourgeois, Jean-Claude Crivello, Pierre Cenedese, Jean-Marc Joubert. Systematic FirstPrinciples Study of Binary Metal Hydrides. ACS Combinatorial Science, 2017, 19 (8), pp.513 - 523. 10.1021/acscombsci.7b00050 . hal-01783928

\section{HAL Id: hal-01783928 \\ https://hal.science/hal-01783928}

Submitted on 17 Mar 2021

HAL is a multi-disciplinary open access archive for the deposit and dissemination of scientific research documents, whether they are published or not. The documents may come from teaching and research institutions in France or abroad, or from public or private research centers.
L'archive ouverte pluridisciplinaire HAL, est destinée au dépôt et à la diffusion de documents scientifiques de niveau recherche, publiés ou non, émanant des établissements d'enseignement et de recherche français ou étrangers, des laboratoires publics ou privés. 


\title{
A systematic first principles study of binary metal hydrides
}

\author{
Natacha Bourgeois, Jean-Claude Crivello, * Pierre Cenedese, and \\ Jean-Marc Joubert \\ Université Paris Est, ICMPE (UMR 7182), CNRS, UPEC, F-94320 Thiais, France \\ E-mail: crivello@icmpe.cnrs.fr
}

\begin{abstract}
First principles calculations were systematically performed for 31 binary metalhydrogen $(M-\mathrm{H})$ systems on a set of 30 potential crystal structures selected on the basis of experimental data and possible interstitial sites. For each $M-\mathrm{H}$ system, the calculated enthalpies of formation were represented as functions of $\mathrm{H}$ composition. The zero point energy correction was considered for the most stable hydrides via additional harmonic phonon calculations. The sequence of stable hydrides (ground-state) given by the convex hull was found in satisfactory agreement with the experimental data. Besides, new high pressure dihydrides and trihydrides were predicted, providing orientations for new materials synthesis. The overall results provide a global overview of hydride relative stabilities and relevant input data for thermodynamic modeling methods.
\end{abstract}

\section{Introduction}

Predicting the formation of reversible metal hydrides is essential in a wide range of environmental issues such as hydrogen storage for energetic use, ${ }^{1,2}$ prevention of structural 
alloys embrittlement ${ }^{3}$ and electrode development for nickel-metal-hydride batteries. ${ }^{4,5}$ The enthalpy of formation $\Delta H_{\text {for }}$ is the key physical quantity because it is linked with the equilibrium pressure via the van't Hoff relation and represents therefore the main contribution to the stability of a given hydride relatively to the pure elements. For this reason, the search for models describing hydride enthalpy of formation induced many studies. The first models in the 1970 s were empirical. ${ }^{6,7}$ The progress in computational science allowed calculations based on the electronic properties, ${ }^{8-13}$ able to provide the enthalpy of formation of stable as well as metastable hydrides. More recently, Density Functional Theory (DFT) systematic studies were carried out ${ }^{14-16}$ considering different hydrides structures, stable as metastable. Smithson ${ }^{14}$ et al. and Miwa and Fukumoto ${ }^{16}$ introduced simultaneously the idea that the formation enthalpy can be divided into three contributions: a positive term resulting from the expansion of the lattice, a positive term needed for a potential structure change and a negative term arising from hydrogen insertion in an expanded lattice.

The previous DFT studies were however limited to a restricted number of crystal structures. The present work intends to screen all the potential binary hydride crystal structure prototypes, on a composition range up to $y=3$, which was not done in previous work. The major interest of our approach is to predict the stable crystal structures and to estimate the metastability of all hydrides.

The selected set of crystal structure prototypes includes (a) the ones experimentally observed among the considered systems and (b) the ones corresponding to all the possible filling of the interstitial sites in basic solid solutions such as face-centered cubic (fcc), bodycentered cubic (bcc), hexagonal close-packed (hcp) and simple cubic structures. The 30 considered prototypes are listed in Table 1 and illustrated in supplementary materials.

High-throughput investigation by massive scale DFT calculations of the energy of formation was performed for 31 metals $M$ distributed in the 30 different $M \mathrm{H}_{y}$ crystal structures prototypes, resulting in 930 hydrides. For each system, the ground-state was determined by the convex hull of the energies of formation as functions of hydrogen composition. 
The present paper is organized as follows: after the methodology description, the predicted ground-states and energies of formation are presented and compared with the experimental data. Finally, the results are discussed in a separate section.

Table 1: Structure prototypes included in the study: $\mathrm{H} / M$ ratio, Prototype name, Pearson Symbol, Space Group (number), Wyckoff Positions, Interstitial site, $M-\mathrm{H}$ system where the structure is observed. When the prototype appears only at high pressure or is considered as metastable for a given $M-\mathrm{H}$ system, the metal is highlighted in italic in the last column. The interstitial sites are described as octahedral (o), tetrahedral (te), triangular (tri) or by the coordination number $(\mathrm{CN})$ when the geometry is more complex. The structures called $\mathrm{PdH}_{y}$ are superstructures of the $\mathrm{NaCl}$ prototype.

\begin{tabular}{|c|c|c|c|c|c|c|}
\hline $\mathrm{H} / M$ & Proto. & P.S. & S.G. & Wyckoff P. & Site & $M-\mathrm{H}$ sys. \\
\hline 0.25 & $\mathrm{PdH}_{0.25}$ & tI8 & $I 4 / m m m(139)$ & $M: 4 c, 4 e, \mathrm{H}: 2 a$ & $\mathrm{O}$ & - \\
\hline 0.5 & $\mathrm{AuTe}_{2}$ & $\mathrm{mC6}$ & $C 2 / m(12)$ & $M: 4 i, \mathrm{H}: 2 a$ & o & $\mathrm{V}$ \\
\hline 0.5 & $\mathrm{TiO}_{2}$-ana & $\mathrm{tI} 12$ & $I 4_{1} /$ amd (141) & $M: 8 e, \mathrm{H}: 4 a$ & $\mathrm{o}$ & $\mathrm{Pd}$ \\
\hline 0.5 & $\mathrm{CdI}_{2}$ & hP3 & $P \overline{3} m 1$ (164) & $M: 2 d, \mathrm{H}: 1 a$ & o & $\mathrm{Tc}$ \\
\hline 0.5 & $\mathrm{Ta}_{2} \mathrm{H}$ & oS6 & $C 222(21)$ & $M: 4 k, \mathrm{H}: 2 a$ & o & $\mathrm{Ta}$ \\
\hline 0.75 & $\mathrm{PdH}_{0.75}$ & tI8 & $I 4 / \mathrm{mmm}(139)$ & $M: 4 c, 4 e, \mathrm{H}: 4 d, 2 b$ & o & - \\
\hline 0.8 & $\mathrm{PdH}_{0.8}$ & $\mathrm{tI} 10$ & $I 4 / m(87)$ & $M: 8 h, 2 a, \mathrm{H}: 8 h$ & o & $\mathrm{Pd}$ \\
\hline 1 & $\mathrm{NbH}_{0.95}$ & oP8 & Pnnn (48) & $M: 4 f, \mathrm{H}: 2 a, 2 b$ & te & $\mathrm{Nb}, T i$ \\
\hline 1 & $\mathrm{PtS}$ & $\mathrm{tP} 4$ & $P 4_{2} / m m c(131)$ & $M: 4 c, \mathrm{H}: 2 a, 2 b$ & te & $\mathrm{Zr}, \mathrm{Ti}$ \\
\hline 1 & $\mathrm{CsCl}$ & $\mathrm{cP} 2$ & $\operatorname{Pm} \overline{3} m(221)$ & $M: 1 a, \mathrm{H}: 1 b$ & $\mathrm{CN}=4$ & $N a, K, R b$ \\
\hline 1 & $\mathrm{NaCl}$ & $\mathrm{cF} 8$ & $F m \overline{3} m(225)$ & $M: 1 a, \mathrm{H}: 1 b$ & $\mathrm{o}$ & $\mathrm{Li}, \mathrm{Na}, \mathrm{K}, \mathrm{Rb}, \mathrm{Ru}, \mathrm{Co}, \mathrm{Rh}, \mathrm{Ni}, \mathrm{Pd}$ \\
\hline 1 & $\mathrm{ZnO}$ & hP4 & $P 6_{3} m c(186)$ & $M: 2 b, \mathrm{H}: 2 b$ & te & $\mathrm{Cu}$ \\
\hline 1 & $\mathrm{CrB}$ & oS8 & Cmcm (63) & $M: 4 c, \mathrm{H}: 4 c$ & $\mathrm{CN}=7$ & Cs \\
\hline 1 & NiAs & hP2 & $P 6_{3} / m m c(194)$ & $M: 2 c, \mathrm{H}: 2 a$ & o & $\mathrm{Cr}, \mathrm{Mn}, \mathrm{Co}$ \\
\hline 1 & anti-NiAs & hP2 & $P 6_{3} / m m c(194)$ & $M: 2 a, \mathrm{H}: 2 c$ & $\mathrm{CN}=6$ & - \\
\hline 1 & $\mathrm{FeH}$ & hP14 & $P 6_{3} / m m c(194)$ & $M: 2 c, 2 a \mathrm{H}: 4 f$ & o & $\mathrm{Fe}$ \\
\hline 1 & $\mathrm{BN}-\mathrm{b}$ & $\mathrm{hP} 2$ & $P 6_{3} / m m c(194)$ & $M: 2 c, \mathrm{H}: 2 d$ & $\operatorname{tr}$ & - \\
\hline 2 & $\mathrm{ReB}_{2}$ & hP6 & $P 6_{3} / m m c(194)$ & $M: 2 c, \mathrm{H}: 4 f$ & te & - \\
\hline 2 & $\mathrm{TiO}_{2}$ & tP6 & $P 4_{2} / m n m(136)$ & $M: 2 a, \mathrm{H}: 4 f$ & $\operatorname{tr}$ & $\mathrm{Mg}$ \\
\hline 2 & $\mathrm{CaF}_{2}$ & $\mathrm{cF} 12$ & $F m \overline{3} m(225)$ & $M: 4 a, \mathrm{H}: 8 c$ & te & $\mathrm{Sc}, \mathrm{Y}, \mathrm{Ti}, \mathrm{Zr}, \mathrm{Hf}, \mathrm{V}, \mathrm{Nb}, \mathrm{Ta}, \mathrm{Cr}, \mathrm{Rh}$ \\
\hline 2 & $\mathrm{PdF}_{2}$ & cP12 & $P a \overline{3}(205)$ & $M: 4 a, \mathrm{H}: 8 c$ & te & $M g$ \\
\hline 2 & $\mathrm{PbO}_{2}$ & oP12 & Pbcn (60) & $M: 4 c, \mathrm{H}: 8 d$ & $\operatorname{tr}$ & $M g$ \\
\hline 2 & $\mathrm{ThH}_{2}$ & tI 6 & I4/mmm (139) & $M: 2 a, \mathrm{H}: 4 d$ & te & $\mathrm{Ti}, \mathrm{Zr}, \mathrm{Hf}$ \\
\hline 2 & $\mathrm{Co}_{2} \mathrm{Si}$ & oP12 & Pnma (62) & $M: 4 c, \mathrm{H}: 4 c$ & te $/ \mathrm{CN}=5$ & $\mathrm{Ca}, \mathrm{Sr}$ \\
\hline 3 & $\mathrm{AuSb}_{3}$ & $\mathrm{cI} 8$ & $\operatorname{Im} \overline{3} m(229)$ & $M: 2 a, \mathrm{H}: 6 b$ & $\mathrm{CN}=2$ & - \\
\hline 3 & $\mathrm{BiF}_{3}$ & cF16 & $F m \overline{3} m(225)$ & $M: 4 a, \mathrm{H}: 4 b, 8 c$ & $o$, te & - \\
\hline 3 & $\operatorname{ReB}_{3}$ & hP8 & $P 6_{3} / m m c(194)$ & $M: 2 c, \mathrm{H}: 2 a, 4 f$ & o, te & - \\
\hline 3 & $\mathrm{HoD}_{3}$ & hP24 & $P \overline{3} c 1(165)$ & $M: 6 f, \mathrm{H}: 12 g, 4 d, 2 a$ & $\operatorname{tri} / \mathrm{CN}=3$ & $\mathrm{Y}$ \\
\hline 3 & $\mathrm{NaH}_{3}$ & hP8 & $P 6_{3} / m m c(194)$ & $M: 2 c, \mathrm{H}: 2 d, 4 f$ & tr, te & - \\
\hline 3 & $\mathrm{Na}_{3} \mathrm{As}$ & hP8 & $P 6_{3} / m m c(194)$ & $M: 2 c, \mathrm{H}: 2 b, 4 f$ & tr, te & $\mathrm{Gd}$ \\
\hline
\end{tabular}




\section{Methodology}

The DFT method ${ }^{17,18}$ which has proven to be one of the most accurate methods for the computation of the electronic structure of hydrides ${ }^{19-22}$ was implemented using the Vienna Abinitio Simulation Package (VASP). ${ }^{23,24}$ The generalized gradient approximation (GGA) was used for the exchange and correlation energy functional with the Perdew-Burke-Ernzerhof functional (PBE). ${ }^{25,26}$ The number of valence electrons considered for each element may be found in supplementary materials. Calculations involving $\mathrm{Co}, \mathrm{Cr}, \mathrm{Fe}, \mathrm{Mn}$ and $\mathrm{Ni}$ elements were carried out with spin polarization. A high energy cutoff of $800 \mathrm{eV}$ was used for the plane wave basis set and a dense grid of k-points in the irreducible wedge of the Brillouin zone was generated with the Monkhorst-Pack scheme. ${ }^{27}$

The cell volume and shape and the atomic positions were relaxed stepwise, using a quasiNewton algorithm. The convergence criterion of $10^{-6} \mathrm{eV}$ was chosen for the total energy. The charge distribution on the atoms was investigated using Bader topological analysis. ${ }^{28,29}$ The energy of gaseous dihydrogen was estimated by the total energy of two hydrogen atoms in an asymmetric box $11 \times 12 \times 13 \AA^{3}$.

For each of the 930 hydrides $M \mathrm{H}_{y}$, the total energy of formation at $0 \mathrm{~K}$ was systematically calculated from the total energies $E_{\mathrm{DFT}}$ of $M \mathrm{H}_{y}\left(E_{\mathrm{DFT}}^{M \mathrm{H}_{y}}\right), \mathrm{H}_{2}$ molecule $\left(E_{\mathrm{DFT}}^{\mathrm{H}_{2}}\right)$ and the pure metal $M\left(E_{\mathrm{DFT}}^{M}\right)$ in its reference state at $0 \mathrm{~K}$, according to equation (1). All energies are given in $\mathrm{kJ} / \mathrm{mol}$ of metal atom.

At zero pressure :

$$
\Delta H_{\mathrm{for}}^{M \mathrm{H}_{y}}=\Delta E_{\mathrm{for}, \mathrm{DFT}}^{M \mathrm{H}_{y}}=E_{\mathrm{DFT}}^{M \mathrm{H}_{y}}-\frac{y}{2} E_{\mathrm{DFT}}^{\mathrm{H}_{2}}-E_{\mathrm{DFT}}^{M}
$$

The zero-point energy (ZPE), arising from atomic displacements around equilibrium positions at $0 \mathrm{~K}$, was determined in the frame of the theory of lattice dynamics, with phonon calculations in the harmonic approximation (HA). Using the frozen phonon (supercell) method ${ }^{30,31}$ the vibrational modes for the metals, hydrides and $\mathrm{H}_{2}$ molecule were 
computed using the phonopy $\operatorname{code}^{32}$ coupled with VASP calculations. For the force calculations, a criterion on forces of $10^{-6} \mathrm{eV} / \AA$ was used in order to eliminate any residual strain. The determined angular frequencies, were summed over all the wave vectors for each mode to obtain the ZPE given by equation within the quantum theory of harmonic crystals. The total contribution to the energy of formation (given in $\mathrm{kJ} / \mathrm{mol}$ of metal atom) is the difference between the ZPE of the hydride $M \mathrm{H}_{y}$ and the pure elements $\mathrm{H}_{2}$ molecule and the pure metal, as:

$$
\Delta E_{\mathrm{ZPE}}^{M \mathrm{H}_{y}}=E_{\mathrm{ZPE}}^{M \mathrm{H}_{y}}-\frac{y}{2} E_{\mathrm{ZPE}}^{\mathrm{H}_{2}}-E_{\mathrm{ZPE}}^{M}
$$

The corrected formation energy $\Delta E_{\text {for,cor }}^{M \mathrm{H}_{y}}$ at $0 \mathrm{~K}$ is thus defined as:

$$
\Delta E_{\mathrm{for}, \mathrm{cor}}^{M \mathrm{H}_{y}}=\Delta E_{\mathrm{DFT}}^{M \mathrm{H}_{y}}+\Delta E_{\mathrm{ZPE}}^{M \mathrm{H}_{y}}
$$

The hydride formation pressures at $300 \mathrm{~K}$ were determined using the equations of state of Joubert for gaseous hydrogen, valid up to $10^{11} \mathrm{~Pa}$ and $1000 \mathrm{~K}^{33}$ and approximating the entropy of formation by the opposite of the gas entropy. Considering the compressibility of the solid phases (hydride and metal) requires heavy calculations and it has been observed in a previous study on $\mathrm{Ni}-\mathrm{H}^{34}$ that the contributions of the hydride and the metal tend to offset each other. Therefore, the resulting energy contribution is not predominant compared to that of the compressibility of the gas phase and was neglected in the present study.

Besides, when a hydride $M \mathrm{H}_{y}$ is formed from a lower hydride $M \mathrm{H}_{x}(x<y)$ we considered the partial formation enthalpy from the intermediate reaction :

$$
M \mathrm{H}_{x}+\frac{y-x}{2} \mathrm{H}_{2} \rightleftharpoons M \mathrm{H}_{y}
$$




\section{Results}

The results for each system are presented below, organized by columns of the periodic table. Only pertinent systems are represented in the present paper. However the figures corresponding to each system are available in supplementary materials. Besides, the calculated energies of formation and charge distributions for each system are compiled in supplementary materials.

In the present section, the DFT calculated energies of formation in $\mathrm{kJ} / \mathrm{mol}-M$ are represented on the figures as functions of hydrogen composition. The energies of the compounds belonging or close to the convex hull, within an enthalpy difference lower than $5 \mathrm{~kJ} / \mathrm{mol}$, were corrected with the ZPE. The corrected energies of formation are represented by black filled squares on the graphs whereas the non corrected values are represented by gray open squares. Experimentally observed prototypes are underlined.

In Table 2 all the experimentally observed prototypes are listed in the second column, for each system. They can be compared to the prototypes predicted by the present calculations, listed in the third column. The experimental and calculated enthalpies of formation are specified. The detailed comparative analysis is done in the discussion section. The calculated total formation energies were compared with two types of experimental data: first, calorimetric measurements, second, formation enthalpy calculated from hydride formation/decomposition pressures measured at different temperatures, via the van't Hoff relation, abbreviated "vH" in the following. Generally, only partial formation enthalpies of hydrides are available in the literature. Therefore, to allow comparisons with the calculated DFT total formation energies, the experimental partial enthalpies of formation were integrated, neglecting the solid solution domains. The list of experimental and calculated values available in the literature are compiled in supplementary materials. 
Table 2: Experimentally observed prototypes compared with the predicted ground-state within $0.5 \mathrm{~kJ} / \mathrm{mol}$. Predicted but never observed prototypes are in italic. Negative phonon frequencies are highlighted with an asterisk. Total experimental and calculated formation enthalpies are indicated in brackets after the prototype.

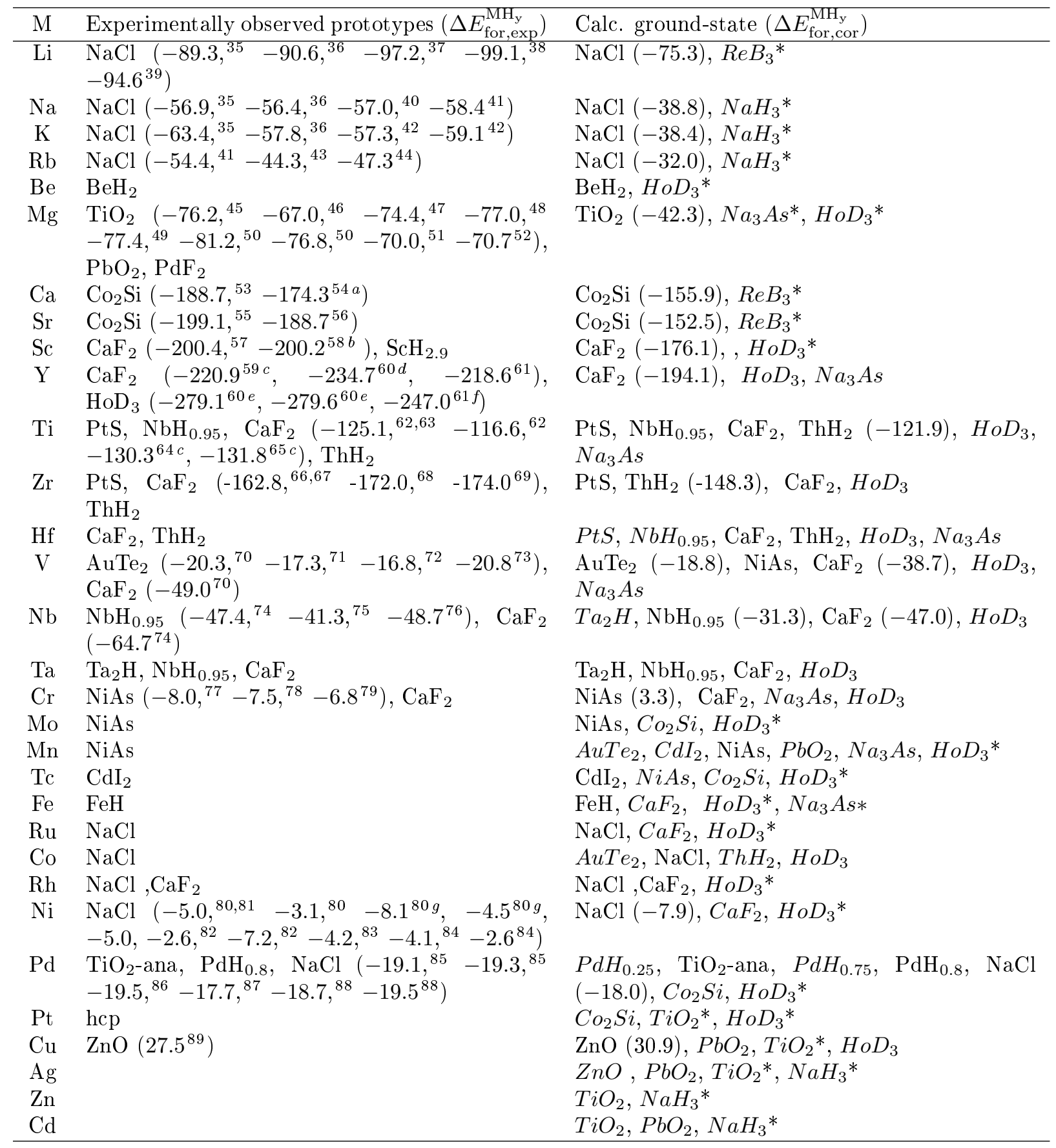

${ }^{a}$ extrapolated at $\mathrm{T}_{\mathrm{amb}}$ by the authors from dissociation pressure measurements carried out between 873 and $1173 \mathrm{~K}$

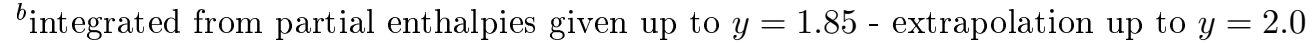

$c_{\text {integrated by the authors }}$

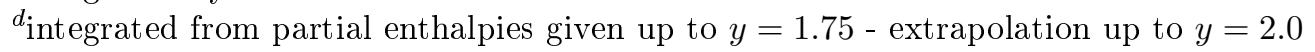

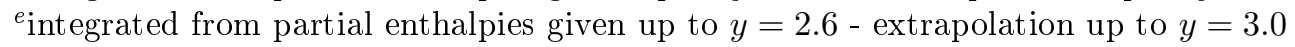

${ }^{f}$ for $y=2.792$

${ }^{g}$ including the pressure work calculation 


\section{Alkaline metals}

The alkaline metals $\mathrm{Li}, \mathrm{Na}, \mathrm{K}$ and $\mathrm{Rb}$ form with hydrogen a stable $\mathrm{NaCl}$ hydride, corresponding to the occupancy of the octahedral (o) sites of a face centered cubic host metallic lattice. Figure 1-left shows a typical picture of relative stabilities predicted by our DFT calculations for the alkaline metals with $\mathrm{Na}$ as an example. All the calculated ground-states included correctly the $\mathrm{NaCl}$ prototype and the dihydride formation is predicted to be very endothermic. For $y \geq 1$ a two-phase equilibrium is predicted involving $\mathrm{NaCl}$ and a trihydride called $\mathrm{NaH}_{3}$ in the present study. However, negative phonon frequencies are calculated for this latter, corresponding to a mechanical instability without pressure work.
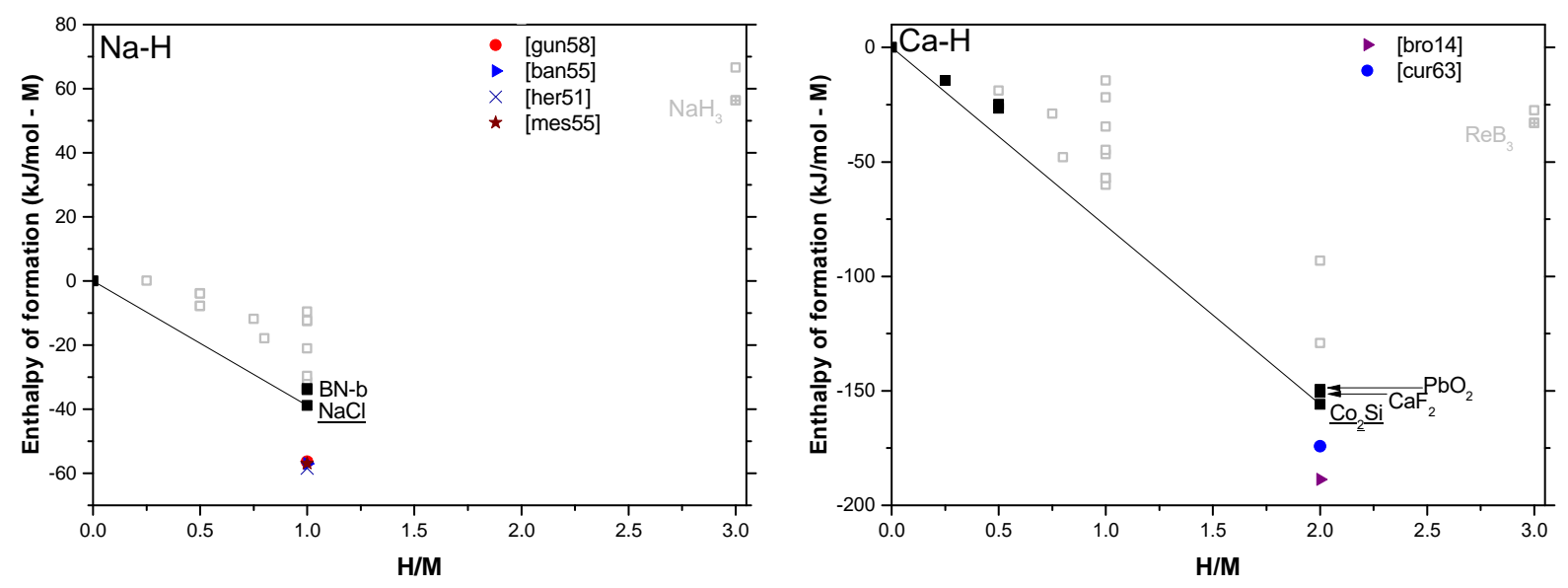

Figure 1: Left: $\mathrm{Na}-\mathrm{H}$ ground-state. Comparison with calorimetric data of Gunn and Green ${ }^{36}$ and vH data of Banus et al. ${ }^{40}$ Hérold, ${ }^{41}$ Messer et al. ${ }^{35}$ Right: Ca-H ground-state. Comparison with calorimetric data of Bronsted ${ }^{53}$ and vH data of Curtis and Chiotti. ${ }^{54}$

\section{Alkaline earth metals}

While alkaline metals form a stable monohydride, the alkaline earth metals are known to form stable dihydrides with various prototypes: body-centered orthorhombic $\mathrm{BeH}_{2}$ for $\mathrm{Be}$, tetragonal $\mathrm{TiO}_{2}$ for $\mathrm{Mg}$ in addition to orthorhombic $\mathrm{PbO}_{2}$ and cubic $\mathrm{PdF}_{2}$ at high pressure and orthorhombic $\mathrm{Co}_{2} \mathrm{Si}$ for both $\mathrm{Ca}$ (Figure 1-right) and Sr. The calculated ground-states were found in agreement with these observations. Besides, the trihydride formation was 
found very endothermic and the corresponding phonon spectra present negative frequencies at the equilibrium volume.

\section{Scandium and yttrium}

The $\mathrm{Sc}-\mathrm{H}$ and $\mathrm{Y}-\mathrm{H}$ systems exhibit very similar behaviors (Figure 2), both forming a dihydride with the $\mathrm{CaF}_{2}$ fluorite type cubic structure via a very exothermic reaction.

Increasing $\mathrm{H}$-composition at $y=3$, the hexagonal $\mathrm{HoD}_{3}$ prototype is observed and above $7.7 \times 10^{9} \mathrm{~Pa}$, a phase transition from $\mathrm{HoD}_{3}$ to a $\mathrm{BiF}_{3}$-type hydride is experimentally reported. ${ }^{90,91}$

The $\mathrm{ScH}_{2.9}$ hydride observed by Antonov et al. ${ }^{92}$ at high pressure in $\mathrm{Sc}-\mathrm{H}$ was not included in the present study because it does not present any long range order. However the short range order is similar to $\mathrm{YH}_{3}$. These features are well predicted by the DFT calculation (Figure 2). The $\mathrm{HoD}_{3}$ prototype is also predicted for $\mathrm{ScH}_{3}$.

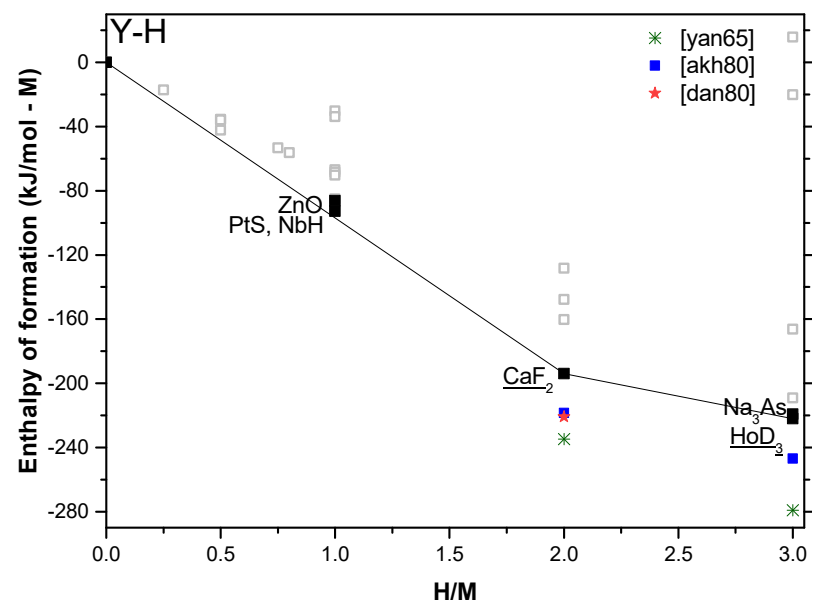

Figure 2: $\mathrm{Y}-\mathrm{H}$ ground-state. Comparison with calorimetric data of Dantzer and Kleppa ${ }^{59}$ and Akhachinskii ${ }^{61}$ and $\mathrm{vH}$ data of Yannopoulos et al. ${ }^{60}$

\section{Titanium, zirconium, hafnium}

$\mathrm{Ti}, \mathrm{Zr}$ and $\mathrm{Hf}$ form a non stoichiometric $\mathrm{CaF}_{2}$ dihydride which deforms to a face-centered tetragonal $\mathrm{ThH}_{2}$ dihydride as the composition approaches $M \mathrm{H}_{2} \cdot{ }^{93,94}$ Moreover, a monohy- 
dride was identified in $\mathrm{Ti}-\mathrm{H}$ and $\mathrm{Zr}-\mathrm{H}$ systems with the same $\mathrm{PtS}$ prototype, corresponding to the occupation of the tetrahedral (te) sites on alternate (110) planes of a fcc metallic lattice. ${ }^{95,96}$ However, no monohydride has ever been observed for Hf-H. Our predicted ground-states include as expected the $\mathrm{ThH}_{2}$ dihydride prototype, slightly more stable than the $\mathrm{CaF}_{2}$ prototype. The PtS prototype lies just on the ground-state line for $\mathrm{Ti}, \mathrm{Zr}$ and unexpectedly also for Hf although this prototype has never been observed (Figure 3). One may note that: on the one hand, for $\mathrm{Ti}-\mathrm{H}$, the calculated enthalpy of formation of the orthorombic $\mathrm{NbH}$ prototype was found very close to the one of the PtS prototype, both presenting tetragonal interstitial sites and, on the other hand, for $\mathrm{ZrH}_{2}$, the enthalpy of formation of the $\mathrm{PbO}_{2}$ prototype was found very close to the one of the $\mathrm{ThH}_{2}$ prototype.
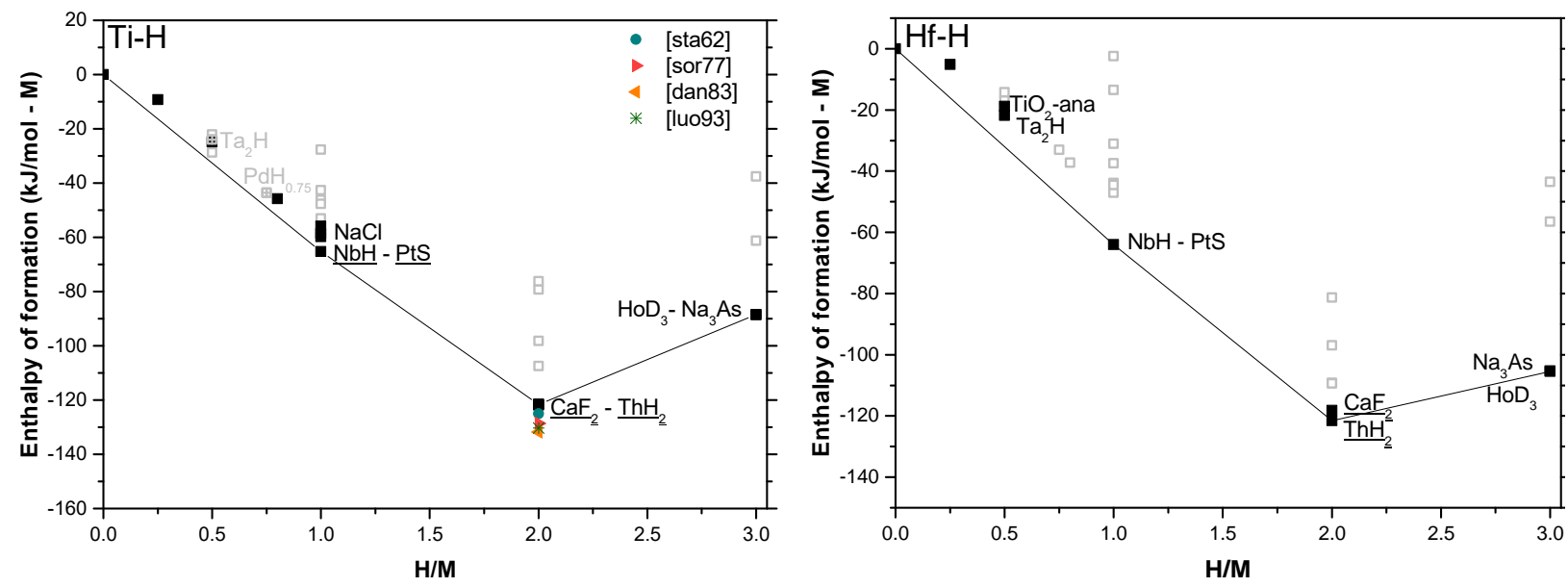

Figure 3: Left: Ti-H ground-state. Comparison with calorimetric data of Luo et al., ${ }^{64}$ Sorokin et al. ${ }^{63}$ Dantzer, ${ }^{65}$ Stalinski and Bieganski. ${ }^{62}$ Right: Hf-H ground-state.

\section{Vanadium, niobium, tantalum}

Both vanadium and tantalum form low concentrated hydrides, in the $\mathrm{AuTe}_{2}$ and $\mathrm{Ta}_{2} \mathrm{H}^{97}$ prototypes, respectively, whereas $\mathrm{Nb}_{2} \mathrm{H}$ has never been observed. Contrary to vanadium, both niobium and tantalum form a monohydride with the same prototype $\mathrm{NbH} .{ }^{98}$ In addition, the $\mathrm{CaF}_{2}$ prototype is observed for $\mathrm{V}-\mathrm{H}$ and $\mathrm{Nb}-\mathrm{H}$, however not for $\mathrm{Ta}-\mathrm{H}$. No trihydride 
has been reported in the literature. The calculations reproduce well these trends (Fig 4). Besides, several features were pointed out for each system:

- for $\mathrm{V}-\mathrm{H}$, numerous monohydrides were calculated near the ground-state,

- for $\mathrm{Nb}-\mathrm{H}$, the $\mathrm{Ta}_{2} \mathrm{H}$ prototype was found on the ground-state,

- for $\mathrm{Ta}-\mathrm{H}$, the dihydride $\mathrm{CaF}_{2}$ is predicted at a pressure of $3.2 \times 10^{9} \mathrm{~Pa}$, the same prototype as $\mathrm{VH}_{2}$ and $\mathrm{NbH}_{2}$.
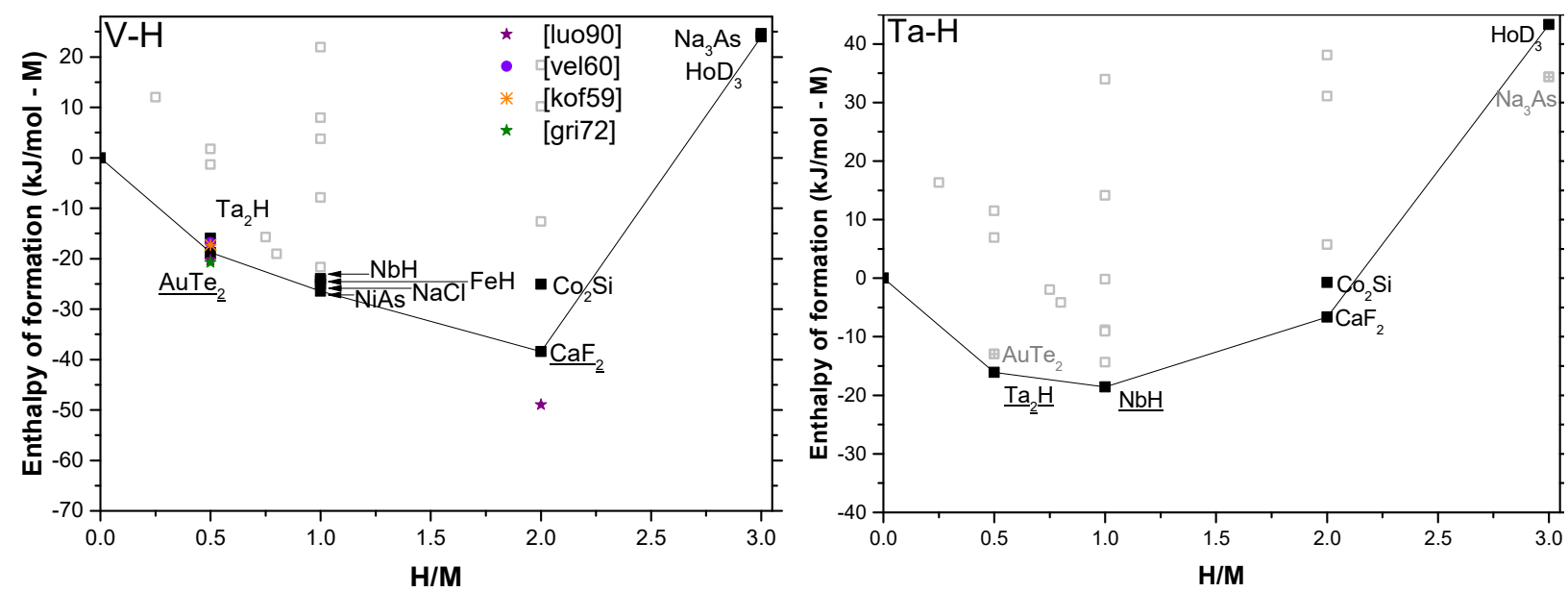

Figure 4: Left: $\mathrm{V}-\mathrm{H}$ ground-state. Comparison with calorimetric data of Luo et al., ${ }^{70} \mathrm{vH}$ data of Veleckis, ${ }^{72}$ Kofstad and Wallace ${ }^{71}$ and Griffiths et al. ${ }^{73}$ Right: Ta-H ground-state.

\section{Columns 6 to 9}

From the 6th column, the hydride enthalpy of formation increases drastically (Figure 5). In fact, for Cr, Mo and Mn a hexagonal hydride with the NiAs prototype is experimentally observed at high pressure, ${ }^{99-103}$ corresponding to a hexagonal-closed-packed (hcp) metallic lattice $\left(P 6_{3} / m m c\right.$ space group) with the octahedral interstitial sites being occupied. Whereas for $\mathrm{Ru}, \mathrm{Co}$ and $\mathrm{Rh}$, the $\mathrm{NaCl}$ prototype is observed in recent high pressure studies at $14 \times 10^{9}$, $9 \times 10^{9}$ and $4 \times 10^{9} \mathrm{~Pa}$, respectively. ${ }^{101,104,105}$ For $\mathrm{Tc}$ and $\mathrm{Mn}$ specifically the prototype $\mathrm{CdI}_{2}$ was identified at $y=0.45$ and $y=0.65$ respectively ${ }^{103,106}$ corresponding to a superstructure 
of NiAs. Besides, the FeH hydride has the characteristic of having a double hcp (dhcp) structure. ${ }^{107}$ High pressure studies also revealed the presence of metastable hcp and fcc hydrides whose compositions are close to FeH. ${ }^{108}$ Dihydrides were only observed for $\mathrm{Cr}$ and $\mathrm{Rh}$, both with the prototype $\mathrm{CaF}_{2}$ as the early transition metals. All the experimentally observed prototypes were found on the ground-states, except $\mathrm{CaF}_{2}$ for $\mathrm{CrH}_{2}$, which is $2.1 \mathrm{~kJ} / \mathrm{mol}$ less stable than $\mathrm{PbO}_{2}$. The calculations confirm all the hydrides which have been previously observed and predict that the higher hydride of Tc has the NiAs structure.
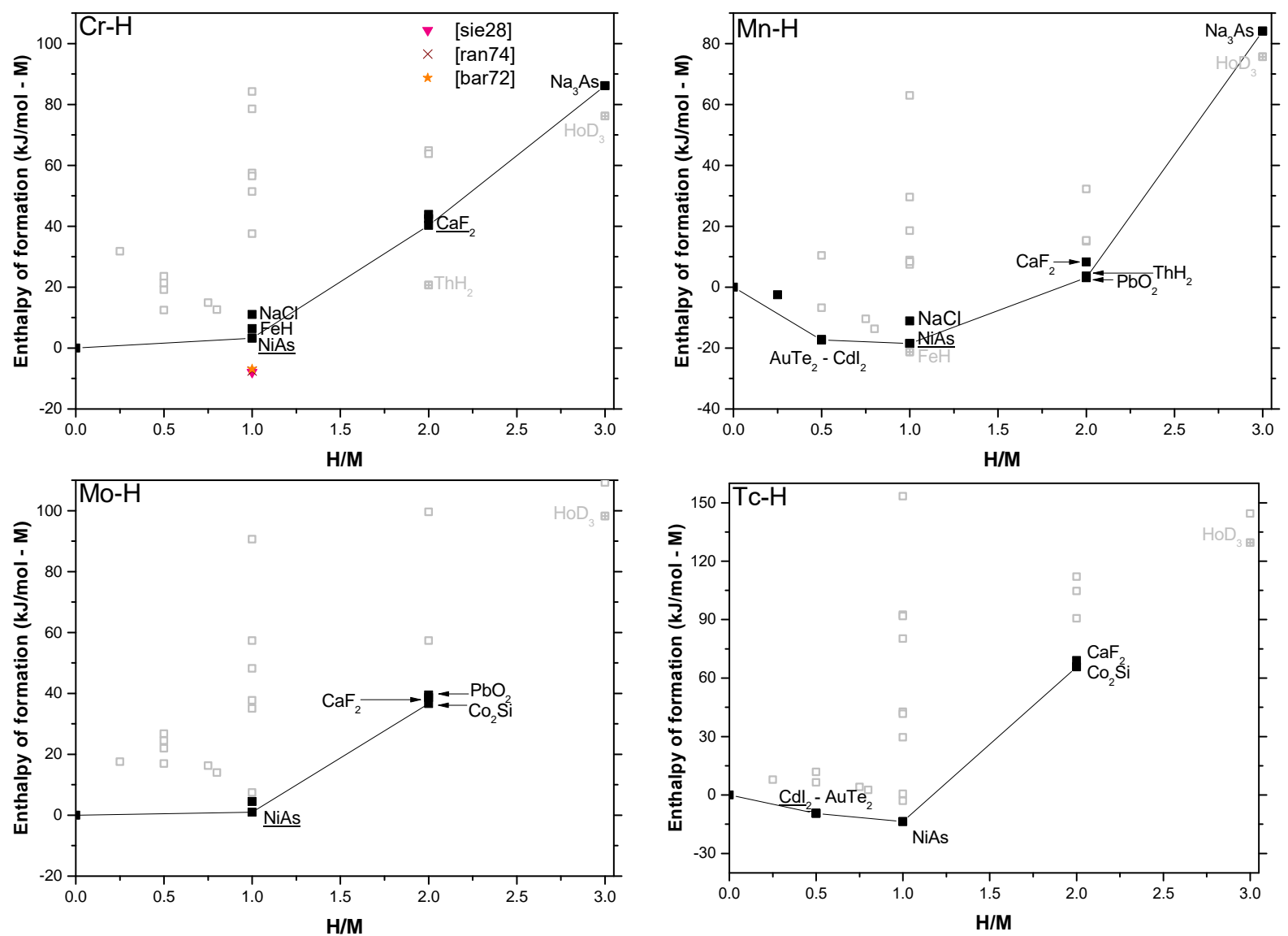

Figure 5: $\mathrm{Cr}-\mathrm{H}, \mathrm{Mo}-\mathrm{H}, \mathrm{Mn}-\mathrm{H}$ and $\mathrm{Tc}-\mathrm{H}$ ground-states. Comparison with calorimetric data of Sieverts and Gotta, ${ }^{77}$ Randzio and Bojarski, ${ }^{78}$ fugacity measurements of Baranowski and Bojarski. ${ }^{79}$ 


\section{Nickel, palladium, platinum}

Experimentally, the $\mathrm{NaCl}$ prototype is observed for both $\mathrm{Pd}$ and $\mathrm{Ni}$ at atmospheric pressure and above $3.2 \times 10^{8} \mathrm{~Pa}$ respectively. Two platinum monohydrides were revealed at a pressure of $2.7 \times 10^{10} \mathrm{~Pa}$ at room temperature, one having a hcp structure, the other an unidentified complex structure. ${ }^{109}$ A transition from octahedral to tetrahedral sites with pressure is suggested. For both $\mathrm{Ni}-\mathrm{H}$ and $\mathrm{Pd}-\mathrm{H}$ systems (Figure 6) the $\mathrm{NaCl}$ prototype is predicted by the DFT calculations. Three other phases are competing with $\mathrm{NaCl}$ in the $\mathrm{Pd}-\mathrm{H}$ system. However the $\mathrm{NaCl}$ prototype is stabilized by the ZPE correction. For $0<y<1$ ordered fcc superstructures are predicted in the $\mathrm{Pd}-\mathrm{H}$ system but not in the $\mathrm{Ni}-\mathrm{H}$ system (see the thermodynamic description of this system $\left.{ }^{34}\right)$.
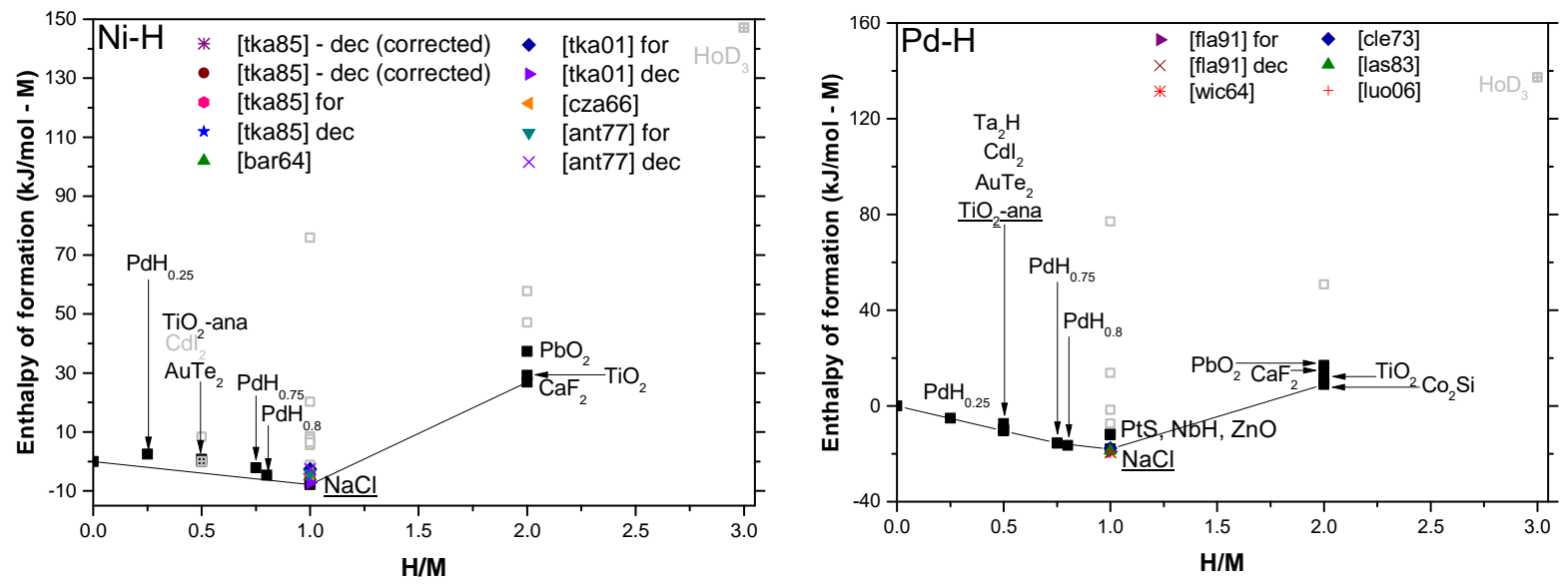

Figure 6: Left: Ni-H ground-state. Comparison with calorimetric data of Tkacz and Baranowski, ${ }^{80}$ Baranowski and Czarnota, ${ }^{81}$ Czarnota and Baranowski, ${ }^{83} \mathrm{vH}$ data extracted from the plateau pressures of Tkacz, ${ }^{82}$ Antonov et al. ${ }^{84}$ Right: $\mathrm{Pd}-\mathrm{H}$ ground-state. Comparison with calorimetric data of Flanagan et al. ${ }^{85}$ and Luo and Flanagan ${ }^{110} \mathrm{vH}$ data of Wicke and Nernst, ${ }^{86}$ Clewley et al. ${ }^{87}$ and Lässer and Klatt. ${ }^{88}$

\section{Columns 11 and 12}

The hydrides of $\mathrm{Cu}, \mathrm{Ag}, \mathrm{Zn}$ and $\mathrm{Cd}$ present only positive energies of formation. A monohydride has been observed only for $\mathrm{Cu}^{111}$ with the $\mathrm{ZnO}$ prototype with an equilibrium pressure measured at $8.4 \times 10^{9} \mathrm{~Pa} .{ }^{112}$ The formation of a dihydride $\mathrm{ZnH}_{2}$ whose structure is unknown 
was also reported. ${ }^{113}$ The prototype $\mathrm{ZnO}$ is correctly predicted by the calculation for $\mathrm{CuH}$, and also for $\mathrm{AgH}$. Contrary to $\mathrm{Cu}-\mathrm{H}$ and $\mathrm{Ag}-\mathrm{H}$, according to the calculation, no monohydride lies on the ground-states of the $\mathrm{Zn}-\mathrm{H}$ and $\mathrm{Cd}-\mathrm{H}$ systems and a two phase equilibrium between the metal and $\mathrm{TiO}_{2}$ is predicted, whose enthalpy of formation is very close to the one of $\mathrm{PbO}_{2}$.

\section{Discussion}

\section{General trends}

The evolution of the calculated formation enthalpy along the periodic table reproduces the observed trends and confirms the different mechanisms, leading either to increase or to decrease the hydride stability. First, the important stability of alkaline, alkaline earth up to Sc and $\mathrm{Y}$ hydrides is driven in particular by the negative enthalpy contribution gained from the charge transfer from the metal cation to hydrogen. The electronegativity difference between hydrogen and the metal represented indeed one of the two parameters in the empirical model of Miedema ${ }^{6}$ for the hydride formation enthalpy. For the first two columns, in agreement with the experimental measurements, the predicted exothermicity of the hydride formation globally decreases with increasing period. This trend may be linked with the decrease of the electronegativity along the same column. The more eletronegative the element is, the more energetically favorable the formation of a $M-\mathrm{H}$ bond is. Second, considering the early transition metals, it has been observed by Beavis ${ }^{114}$ that, from the 3rd to the 5th column, the $4 d$ element forms the most stable dihydride and trihydride. Our calculations confirmed this trend for these 3 columns, in relation with the decrease of the lattice parameter from the $4 d$ to the $5 d$ metals. Third, the shift towards positive enthalpies of formation with increasing atomic number has been linked with the increase of the cohesion of the metals up to the 8 th column $(\mathrm{Fe})$ where the $d$ bands are half filled. ${ }^{14,16}$ Consequently, in the middle of the $d$ elements the metal total enthalpy $E_{\mathrm{DFT}}^{M}$ reaches a minimum and the cost of the 
lattice expansion for hydrogen insertion a maximum. Hence, the interatomic distances tend to decrease along the $d$-metals up to the 8th column. According to the calculations of Miwa and Fukumoto ${ }^{16}$ this is a dominant factor, leading to a decrease of the negative chemical enthalpy contribution arising from the $M-\mathrm{H}$ bonds formation, irrespective of the nature of the metal.

\section{Ground-state structure prediction}

The present methodology was able to predict correctly all the experimentally observed hydrides, except for Pt. In addition, new metastable hydrides and high pressure hydrides were found on the ground-state at $0 \mathrm{~K}$. The predicted prototypes are summarized in Table 2, compared with the experimental ground-states. Key results are discussed below, starting with the early transition metals. The monohydrides HfH and YH were found stable with the prototypes $\mathrm{NbH}$ and $\mathrm{PtS}$, whose formation energies were equal to within $0.5 \mathrm{~kJ} / \mathrm{mol}$. These two prototypes have not been observed for Hf and Y yet but they are stable for other early transition metals: the PtS prototype for $\mathrm{Ti}^{95,96}$ and $\mathrm{Zr}$ and the $\mathrm{NbH}$ prototype is well known for $\mathrm{Nb}$ and $\mathrm{Ta}$ and was also observed for Ti. Interestingly, a hcp monohydride $\mathrm{VH}$ was found stable at $0 \mathrm{~K}$, in competition with other structures. This result implies that a monohydride VH may be easily stabilized by adding chemical defects. Moreover, like all the other early transition metals, a dihydride $\mathrm{TaH}_{2}$ is predicted with the $\mathrm{CaF}_{2}$ prototype at $3.2 \times 10^{9} \mathrm{~Pa}$. The columns 6 to 12 of the periodic table are now discussed, starting with the $M \mathrm{H}$ stoichiometry. The o-site NiAs prototype, observed for $\mathrm{Cr}$, Mo and $\mathrm{Mn}$, is correctly predicted by the calculations. In agreement with this trend, the same prototype is also predicted for Tc at $2.1 \times 10^{8} \mathrm{~Pa}$, in accordance with the prevalence of o-sites for monohydrides after the 6 th column. One may note that the prototype $\mathrm{CdI}_{2}$ observed for $\mathrm{Tc}-\mathrm{H}$ is also predicted for $\mathrm{Mn}-$ $\mathrm{H}$, with a formation enthalpy close to that of $\mathrm{AuTe}_{2}$, although it has never been observed. The 8th column appeared as a transition from hexagonal towards cubic monohydrides. For $\mathrm{FeH}$, the metastable NiAs prototype was found $1.4 \mathrm{~kJ} / \mathrm{mol}$ less stable than the dhcp FeH 
prototype, in agreement with the observation of Antonov et al. ${ }^{115}$

In contrast with the two previous columns, $\mathrm{RuH}$ is predicted with the $\mathrm{NaCl}$ prototype at $5.9 \times 10^{9} \mathrm{~Pa}$, in agreement with the recent high pressure study of Kuzovnikov and Tkacz ${ }^{104}$ and with the calculations of Liu et al. ${ }^{116}$ The calculated equilibrium pressure was found close to the measured decomposition pressure of $6.2 \times 10^{9} \mathrm{~Pa}$. The $\mathrm{NaCl}$ prototype is also predicted for $\mathrm{CoH}, \mathrm{RhH}, \mathrm{NiH}$, and $\mathrm{PdH}$ in agreement with the experimental observations. Besides, the lower composition hydrides predicted for $\mathrm{Pd}-\mathrm{H}$ for $0<y<1$ correspond to different orderings of hydrogen atoms on the interstitial sites of the fcc host lattice. Two of them are indeed experimentally observed at low temperature. ${ }^{117}$ Interestingly, no monohydride is predicted for the Pt-H system, contrary to the experimental observations at high pressure. The error is probably due to the pressure work which may considerably affect the relative stabilities at the considered pressures. A complementary study is necessary to include this effect.

Besides, the hydride $\mathrm{AgH}$ is predicted with the prototype $\mathrm{ZnO}$, which was experimentally observed for $\mathrm{CuH}$. From the 6th to 12 th column, only two dihydrides were experimentally observed: $\mathrm{CrH}_{2}$ and $\mathrm{RhH}_{2}$, both having the $\mathrm{CaF}_{2}$ prototype. They are correctly predicted by the calculations. Furthermore, a competition between the $\mathrm{CaF}_{2}$ and $\mathrm{PbO}_{2}$ prototypes is predicted for the $3 d$ metal dihydrides and between the $\mathrm{Co}_{2} \mathrm{Si}$ and $\mathrm{CaF}_{2}$ prototypes for the $4 d$, the $\mathrm{TiO}_{2}$ prototype appearing only for the 12 th column, as summarized in Table 3 .

Table 3: Dihydride structure prototypes predicted on the ground-state for each $3 d$ and $4 d$ metal from the 6 th to the 12 th column, associated with the predicted formation pressure.

\begin{tabular}{ccccccc}
\hline 6 & 7 & 8 & 9 & 10 & 11 & 12 \\
\hline $\mathrm{Cr}$ & $\mathrm{Mn}$ & $\mathrm{Fe}$ & $\mathrm{Co}$ & $\mathrm{Ni}$ & $\mathrm{Cu}$ & $\mathrm{Zn}$ \\
$\mathrm{PbO}_{2}$ & $\mathrm{PbO}_{2}$ & $\mathrm{CaF}_{2}$ & $\mathrm{CaF}_{2}$ & $\mathrm{CaF}_{2}$ & $\mathrm{PbO}_{2}$ & $\mathrm{TiO}_{2}$ \\
$1.0 \times 10^{10} \mathrm{~Pa}$ & $5.3 \times 10^{9} \mathrm{~Pa}$ & $9.8 \times 10^{9} \mathrm{~Pa}$ & $9.3 \times 10^{9} \mathrm{~Pa}$ & $8.7 \times 10^{9} \mathrm{~Pa}$ & $2.0 \times 10^{10} \mathrm{~Pa}$ & $8.8 \times 10^{9} \mathrm{~Pa}$ \\
\hline $\mathrm{Mo}$ & $\mathrm{Tc}$ & $\mathrm{Ru}$ & $\mathrm{Rh}$ & $\mathrm{Pd}$ & $\mathrm{Ag}$ & $\mathrm{Cd}$ \\
$\mathrm{Co}_{2} \mathrm{Si}$ & $\mathrm{Co}_{2} \mathrm{Si}$ & $\mathrm{CaF}_{2}$ & $\mathrm{CaF}_{2}$ & $\mathrm{Co}_{2} \mathrm{Si}$ & $\mathrm{PbO}_{2}$ & $\mathrm{PbO}_{2}-\mathrm{TiO}_{2}$ \\
$9.0 \times 10^{9} \mathrm{~Pa}$ & $2.4 \times 10^{10} \mathrm{~Pa}$ & $1.5 \times 10^{10} \mathrm{~Pa}$ & $2.1 \times 10^{9} \mathrm{~Pa}$ & $6.6 \times 10^{9} \mathrm{~Pa}$ & $2.8 \times 10^{10} \mathrm{~Pa}$ & $1.2 \times 10^{10} \mathrm{~Pa}$ \\
\hline
\end{tabular}

Within the set of metals included in the study, trihydrides are experimentally observed only for $\mathrm{Y}$ and $\mathrm{Sc}$ with the $\mathrm{HoD}_{3}$ prototype - without long range order for $\mathrm{ScH}_{3}$. As 
expected, trihydrides of column 1 and 2 were predicted highly unstable. The prototype $\mathrm{HoD}_{3}$ is also predicted without negative phonon frequencies for $\mathrm{NbH}_{3}, \mathrm{TaH}_{3}, \mathrm{TiH}_{3}$ and $\mathrm{ZrH}_{3}$ at $1.3 \times 10^{10} \mathrm{~Pa}, 1.3 \times 10^{10} \mathrm{~Pa}, 8.3 \times 10^{9} \mathrm{~Pa}$ and $3.3 \times 10^{9} \mathrm{~Pa}$, respectively.

\section{Quantitative agreement}

The ZPE correction $\Delta E_{\mathrm{ZPE}}^{M \mathrm{H}_{y}}$ was found to be non negligible. For te-sites, its value was always found positive, destabilizing, reaching $22 \mathrm{~kJ} / \mathrm{mol}$ for $\mathrm{VH}_{2}$ whereas for octahedral and other sites it may be either positive or negative. Neglecting the ZPE contribution leads thus to overestimate the stability of te-site prototypes, as it will be detailed in a future publication. For instance, the ZPE contribution is responsible for the stabilization of the $\mathrm{NaCl} \mathrm{PdH}$ hydride against 3 tetrahedral hydrides $\mathrm{PtS}, \mathrm{NbH}$ and $\mathrm{ZnO}$, predicted as more stable by the raw DFT calculations. Again, for the Rh-H system, the raw DFT calculations predict the $\mathrm{CaF}_{2}$ hydride as the first one to be formed. As the $\mathrm{NaCl}$ hydride is stabilized by the ZPE contribution whereas the $\mathrm{CaF}_{2}$ is destabilized, the correction brings the ground-state in agreement with the experimental observations. ${ }^{105}$

Comparing with the available experimental data, the magnitude of the hydride formation enthalpies seems to be globally underestimated by the calculations, in particular for alkaline and alkaline earth hydrides. The difference reaches about $20 \mathrm{~kJ} / \mathrm{mol}$ for $\mathrm{KH}$ and softens from the left to the right of the periodic table. This difference could originate from the fact that experiments are carried out at non zero temperatures whereas the calculations are performed at $0 \mathrm{~K}$. Indeed, because the reference states of the metals and hydrides (solid) and the $\mathrm{H}_{2}$ molecule (gaseous) are different, the Kopp-Neumann rule cannot be applied: the hydride heat capacity cannot be estimated by an average between that of gaseous dihydrogen and of the corresponding pure metal. As a consequence, the variation of the formation enthalpy $\Delta H_{\text {for }}^{M \mathrm{H}_{y}}$ with the temperature should be larger than for reactions involving only metals. The difference between experimental data at non zero temperature and calculations at $0 \mathrm{~K}$ is thus expected to be larger. To make meaningful comparisons, extrapolations should be 
carried out on the basis of heat capacity values, requesting an additional study. Besides, some experiments are carried out under high hydrogen pressure whereas the calculations are performed without mechanical pressure. Therefore, without corrections, the high pressure calorimetric data tend to be shifted towards positive values, because of the neglected pressure works affecting especially the gas phase. In order to compare with the DFT, the calorimetric values have to be corrected, as it has been done for nickel. ${ }^{80}$ When the volumes of the condensed phases are affected, more complex models are needed, which involve the corresponding volume variations with $T$ and $P$ (see e.g. the treatment done in [ 34]).

\section{Conclusion}

For each investigated $M-\mathrm{H}$ system, the experimentally observed prototypes were correctly predicted on the ground-state. Besides, the calculated total hydride formation enthalpies at $0 \mathrm{~K}$, were found consistent with the available experimental values. The temperature variation of the enthalpies represents a point to be investigated in future studies.

Our systematic approach is complementary to both the experimental methods or evolutionary algorithms, ${ }^{118}$ as the latter predicts the stable crystal structures. Whereas the present database includes the metastable hydrides, giving an exhaustive picture of the relative stabilities between the different considered crystal structures. Trends which are only outlined by experimental results can be confirmed by broadening the set of hydrides. Thus, prototypes which are close to be stable at $0 \mathrm{~K}$ can be highlighted, as the monohydride $\mathrm{VH}$, as well as higher hydrides $\mathrm{TaH}_{2}$ or $\mathrm{ZrH}_{3}$ whose formation pressure can be estimated. Experiments are needed to confirm these predictions.

The obtained results represent useful input data to supply thermodynamic database usable in the frame of prediction algorithms, like the machine learning. ${ }^{119}$ They can also be used in thermodynamic modeling, such as the Calphad approach, ${ }^{120}$ allowing to easily combine the binary systems to obtain predictions in the ternary and higher systems. Such 
outlooks represent promising tools for the alloy design of hydrogen storage alloys or to improve the alloy durability towards hydrogen embrittlement.

\section{Acknowledgement}

This work has benefited from a French government grant managed by ANR within the framework of the national program Investments for the Future ANR-11-LABX-022-01. DFT calculations were performed using HPC resources from GENCI-CINES (Grant 2016-96175).

\section{Supporting Information Available}

The following files are available free of charge.

- 1-Crystal-structures: information and illustration of the considered hydride crystal structures including hydrogen composition, prototype, Pearson symbol, space group and Wyckoff positions

- 2-Formation-enthalpies-per-system_graphs: graphical representation of the calculated formation enthalpies as function of hydrogen composition for each considered system, ground-states

- 3-Formation-enthalpies-per-system_values: calculated formation enthalpies, charge distributions and magnetic moments of the 30 crystal prototypes for each of the 31 considered systems

- 4-Literature-review: experimental and calculated hydride formation enthalpies available in the literature

\section{References}

(1) Züttel, A. Materials for hydrogen storage. Mater. Today 2003, 6, 24-33. 
(2) Schlapbach, L. Technology: Hydrogen-fuelled vehicles. Nature 2009, 460, 809-811.

(3) Hirth, J. P. Effects of hydrogen on the properties of iron and steel. Metall. Trans. A 1980, 11, 861-890.

(4) Cuevas, F.; Joubert, J.-M.; Latroche, M.; Percheron-Guégan, A. Intermetallic compounds as negative electrodes of Ni/MH batteries. Applied Physics A 2001, 72, 225238.

(5) Joubert, J.-M.; Latroche, M.; Percheron-Guégan, A. Metallic hydrides II: Materials for electrochemical storage. MRS Bull. 2002, 27, 694-698.

(6) Miedema, A. The electronegativity parameter for transition metals: Heat of formation and charge transfer in alloys. J. Less Common Met. 1973, 32, 117-136.

(7) Bouten, P. C. P.; Miedema, A. R. On the heats of formation of the binary hydrides of transition metals. J. Less Common Met. 1980, 71, 147-160.

(8) Gelatt, C. D.; Ehrenreich, H.; Weiss, J. A. Transition-metal hydrides: Electronic structure and the heats of formation. Phys. Rev. B 1978, 17, 1940-1957.

(9) Williams, A. R.; Kübler, J.; Gelatt, C. D. Cohesive properties of metallic compounds: Augmented-spherical-wave calculations. Phys. Rev. B 1979, 19, 6094-6118.

(10) Methfessel, M.; Kubler, J. Bond analysis of heats of formation: application to some group VIII and IB hydrides. J. Phys. F: Met. Phys. 1982, 12, 141.

(11) Ho, K. M.; Tao, H. J.; Zhu, X. Y. First-principles investigation of metal-hydrogen interactions in NbH. Phys. Rev. Lett. 1984, 53, 1586-1589.

(12) Papaconstantopoulos, D. A.; Switendick, A. C. Calculations of the electronic properties of substoichiometric Ti-Fe hydride. Phys. Rev. B 1985, 32, 1289-1300. 
(13) Joubert, J.-M.; Crivello, J.-C. Stability of erbium hydrides studied by DFT calculations. Int. J. Hydrogen Energy 2012, 37, 4246-4253.

(14) Smithson, H.; Marianetti, C. A.; Morgan, D.; Van der Ven, A.; Predith, A.; Ceder, G. First-principles study of the stability and electronic structure of metal hydrides. Phys. Rev. B 2002, 66, 144107-1-144107-10.

(15) Wolverton, C.; Ozolin̦š, V.; Asta, M. Hydrogen in aluminum: First-principles calculations of structure and thermodynamics. Phys. Rev. B 2004, 69, 144109-1-144109-16.

(16) Miwa, K.; Fukumoto, A. First-principles study on $3 d$ transition-metal dihydrides. Phys. Rev. B 2002, 65, 155114-1-155114-7.

(17) Hohenberg, P.; Kohn, W. Inhomogeneous Electron Gas. Phys. Rev. 1964, 136, B864B871.

(18) Kohn, W.; Sham, L. J. Self-consistent equations including exchange and correlation effects. Phys. Rev. 1965, 140, A1133-A1138.

(19) Takagi, S.; Iijima, Y.; Sato, T.; Saitoh, H.; Ikeda, K.; Otomo, T.; Miwa, K.; Ikeshoji, T.; Aoki, K.; Orimo, S.-i. True Boundary for the Formation of Homoleptic Transition-Metal Hydride Complexes. Angewandte Chemie International Edition 2015, 54, 5650-5653.

(20) Takagi, S.; Orimo, S.-i. Recent progress in hydrogen-rich materials from the perspective of bonding flexibility of hydrogen. Scripta Materialia 2015, 109, 1 - 5 .

(21) Reshak, A. $\mathrm{MgH}_{2}$ and $\mathrm{LiH}$ metal hydrides crystals as novel hydrogen storage material: Electronic structure and optical properties. Int. J. Hydrogen Energy 2013, 38, 1194611954.

(22) Reshak, A. $\mathrm{NaMgH}_{3}$ a perovskite-type hydride as advanced hydrogen storage systems: Electronic structure features. Int. J. Hydrogen Energy 2015, 40, 16383-16390. 
(23) Kresse, G.; Furthmüller, J. Efficient iterative schemes for ab initio total-energy calculations using a plane-wave basis set. Phys. Rev. B 1996, 54, 11169-11186.

(24) Kresse, G.; Joubert, D. From ultrasoft pseudopotentials to the projector augmentedwave method. Phys. Rev. B 1999, 59, 1758-1775.

(25) Perdew, J. P.; Ernzerhof, M.; Burke, K. Rationale for mixing exact exchange with density functional approximations. J. Chem. Phys. 1996, 105, 9982-9985.

(26) Perdew, J. P.; Burke, K.; Ernzerhof, M. Generalized gradient approximation made simple. Phys. Rev. Lett. 1996, 77, 3865-3868.

(27) Monkhorst, H. J.; Pack, J. D. Special points for Brillouin-zone integrations. Phys. Rev. $B$ 1976, 13, 5188-5192.

(28) Bader, R. Atoms in molecules. A quantum theory.; Clarendon Press: Oxford, UK, 1990.

(29) Henkelman, G.; Arnaldsson, A.; Jónsson, H. A fast and robust algorithm for Bader decomposition of charge density. Comput. Mater. Sci. 2006, 36, 354-360.

(30) Kunc, K.; Martin, R. M. Density-functional calculation of static and dynamic properties of GaAs. Phys. Rev. B 1981, 24, 2311-2314.

(31) Yin, M. T.; Cohen, M. L. Theory of lattice-dynamical properties of solids: Application to Si and Ge. Phys. Rev. B 1982, 26, 3259-3272.

(32) Togo, A.; Tanaka, I. First principles phonon calculations in materials science. Scr. Mater. 2015, 108, 1-5.

(33) Joubert, J.-M. A Calphad-type equation of state for hydrogen gas and its application to the assessment of Rh-H system. Int. J. Hydrogen Energy 2010, 35, 2104-2111. 
(34) Bourgeois, N.; Crivello, J.-C.; Saengdeejing, A.; Chen, Y.; Cenedese, P.; Joubert, J.M. Thermodynamic modeling of the Ni-H system. J. Phys. Chem. C 2015, 119, $24546-24557$.

(35) Messer, C. E.; Fasolino, L. G.; Thalmayer, C. E. The heats of formation of lithium, sodium and potassium hydrides. J. Am. Chem. Soc. 1955, 77, 4524-4526.

(36) Gunn, S. R.; Green, L. G. The heats of formation at $25^{\circ}$ of the crystalline hydrides and deuterides and aqueous hydroxides of lithium, sodium and potassium. J. Am. Chem. Soc. 1958, 80, 4782-4786.

(37) Veleckis, E. Decomposition pressures in the $(\alpha+\beta)$ fields of the $\mathrm{Li}-\mathrm{LiH}, \mathrm{Li}-\mathrm{LiD}$, and Li-LiT systems. J. Nucl. Mater. 1979, 79, 20-27.

(38) Smith, H.; Webb, R. Equilibrium dissociation pressure of LiH and LiD; 1977.

(39) Simandl, R. F. Equilibrium-pressure isotherms for the system lithium-lithium hydridehydrogen at 823, 873 and 923 K; 1981.

(40) Banus, M. D.; McSharry, J. J.; Sullivan, E. A. The sodium-sodium hydride-hydrogen system at 500-600. J. Am. Chem. Soc. 1955, r7, 2007-2010.

(41) Hérold, A. Contribution to the study of the alkali hydrides. Ann. Chim. Phys. 1951, $6,536-581$.

(42) Arnoult, W. J.; McLellan, R. B. Thermodynamics of transition metal alloys. Acta Metall. 1973, 21, 1397-1403.

(43) Hackspill, L.; Borocco, A. The preparation of alkali deuterides and a comparison of their dissociation pressures with those of the corresponding hydrides. Bull. Soc. Chim. Fr. 1939, 6, 91-103.

(44) Messer, C. E.; Homonoff, H.; Nickerson, R. F.; Gibb, T. R. P. Light Metal Hydrides for Shielding Components; 1953. 
(45) Post, M. L.; Murray, J. J.; Taylor, J. B. Metal hydride studies at the National Research Council of Canada. Int. J. Hydrogen Energy 1984, 9, 137-145.

(46) Ellinger, F. H.; Holley Jr, C. E.; McInteer, B. B.; Pavone, D.; Potter, R. M.; Staritzky, E.; Zachariasen, W. H. The preparation and some properties of magnesium hydride. J. Am. Chem. Soc. 1955, 77, 2647-2648.

(47) Stampfer, J.F. Holley, C.E. Suttle, J. The magnesium-hydrogen system. J. Am. Chem. Soc. 1960, 82, 3504-3508.

(48) Tanguy, B.; Soubeyroux, J.; Pezat, M. Amélioration des conditions de synthèse de l'hydrure de magnesium à l'aide d'adjuvants. Mater. Res. Bull. 1976, 11, 1441-1447.

(49) Reilly, J. J.; Wiswall, R. H. Reaction of hydrogen with alloys of magnesium and nickel and the formation of $\mathrm{Mg}_{2} \mathrm{NiH}_{4}$. Inorg. Chem. 1968, 7, 2254-2256.

(50) Gross, K. J.; Spatz, P.; Züttel, A.; Schlapbach, L. Mechanically milled Mg composites for hydrogen storage the transition to a steady state composition. J. Alloys Compd. 1996, 240, 206-213.

(51) Pedersen, A.; Kjøller, J.; Larsen, B.; Vigeholm, B. Magnesium for hydrogen storage. Int. J. Hydrogen Energy 1983, 8, 205-211.

(52) Selvam, P. Studies on the thermal characteristics of hydrides of $\mathrm{Mg}, \mathrm{Mg}_{2} \mathrm{Ni}, \mathrm{Mg}_{2} \mathrm{Cu}$ and $\mathrm{Mg}_{2} \mathrm{Ni}_{1-x} \mathrm{M}_{x}(\mathrm{M}=\mathrm{Fe}, \mathrm{Co}, \mathrm{Cu}$ or $\mathrm{Zn} ; 0<\mathrm{x}<1)$ alloys. Int. J. Hydrogen Energy 1988, 13, 87-94.

(53) Bronsted, J. N. Thermodynamics of calcium hydride formation. Z. Elektrochem. Angew. Phys. Chem. 1914, 20, 81-83.

(54) Curtis, R. W.; Chiotti, P. Thermodynamic properties of calcium hydride. J. Phys. Chem. 1963, 67, 1061-1065. 
(55) Banus, M. D.; Bragdon W., R. A survey of hydrides; 1952.

(56) Guntz, A.; Benoit, F. The heat of reaction of alkaline earth metals with oxygen, hydrogen and nitrogen. Ann. Chim. 1923, 20, 5-33.

(57) Stampfer, J. F. The scandium-hydrogen system; 1966.

(58) Lieberman, M. L.; Wahlbeck, P. G. The thermodynamics of the scandium-hydrogen system. J. Phys. Chem. 1965, 69, 3514-3519.

(59) Dantzer, P. G.; Kleppa, O. J. High temperature thermodynamics of the yttriumhydrogen systems. J. Chem. Phys. 1980, 73, 5259-5263.

(60) Yannopoulos, L. N.; Edwards, R. K.; Wahlbeck, P. G. The thermodynamics of the yttrium-hydrogen system. J. Phys. Chem. 1965, 69, 2510-2515.

(61) Akhachinskii, V. V. Enthalpy of formation of $\mathrm{YH}$ and $\mathrm{YH}_{2.792}$. Proceeding of the International Symposium on Thermodynamics of Nuclear Materials, IAEA. Julich, 1980; pp 155-160.

(62) Stalinski, B.; Bieganski, Z. Thermodynamical properties of nonstoichiometric titanium hydrides within range $24^{\circ}$ to $360^{\circ}$ K. Bull. Acad. Pol. Sci., Ser. Sci. Chim. 1962, 10, $243-248$.

(63) Sorokin, V. P.; Levakov, E. V.; Malyshev, A. Y. Heat of sorption of hydrogen by titanium at 295 K. Russ. J. Phys. Chem 1977, 51, 1635-1636.

(64) Luo, W.; Flanagan, T. B.; Clewley, J. D.; Dantzer, P. Calorimetrically measured enthalpies for the reaction of Hf with $\mathrm{H}(\mathrm{D})_{2}$ (g). Metall. Trans. A 1993, 24, 26232627.

(65) Dantzer, P. High temperature thermodynamics of $\mathrm{H}_{2}$ and $\mathrm{D}_{2}$ in titanium, and in dilute titanium oxygen solid solutions. J. Phys. Chem. Solids 1983, 44, 912-923. 
(66) Rundle, R.; Wilson, A.; Nottorf, R.; Raeuchle, R. The crystal structures of ThH $H_{2}$ and $\mathrm{ZrH}_{2} ; 1948$.

(67) Fredrickson, D. R.; Nuttall, R. L.; Flotow, H. E.; Hubbard, W. N. The enthalpies of formation of zirconium dihydride and zirconium dideuteride. J. Phys. Chem. 1963, $67,1506-1509$.

(68) Turnbull, A. Heats of formation of zirconium hydrides. Aust. J. Chem. 1964, 17, 1063-1071.

(69) Dantzer, P.; Luo, W.; Flanagan, T. B.; Clewley, J. D. Calorimetrically measured enthalpies for the reaction of $\mathrm{H}_{2}(\mathrm{~g})$ with $\mathrm{Zr}$ and $\mathrm{Zr}$ alloys. Metall. Trans. A 1993, 24, $1471-1479$.

(70) Luo, W.; Clewley, J. D.; Flanagan, T. B. Thermodynamics and isotope effects of the vanadium-hydrogen system using differential heat conduction calorimetry. J. Chem. Phys. 1990, 93, 6710-6722.

(71) Kofstad, P.; Wallace, W. E. Vapor pressure studies of the vanadium-hydrogen system and thermodynamics of formation of vanadium-hydrogen solid solutions. J. Am. Chem. Soc. 1959, 81, 5019-5022.

(72) Veleckis, E. The thermodynamic properties of the systems $\mathrm{Nb}-\mathrm{H}, \mathrm{V}-\mathrm{H}$, and $\mathrm{Ta}-\mathrm{H}$. Ph.D. thesis, Illinois Inst. of Tech., Chicago, 1960.

(73) Griffiths, R.; Pryde, J. A.; Righini-Brand, A. Phase diagram and thermodynamic data for the hydrogen/vanadium system. J. Chem. Soc., Faraday Trans. 1 1972, 68, $2344-2349$.

(74) Luo, W.; Kuji, T.; Clewley, J. D.; Flanagan, T. B. The thermodynamic properties of the niobium-hydrogen system measured by reaction calorimetry. J. Chem. Phys. 1991, 94, 6179-6189. 
(75) Pryde, J. A.; Titcomb, C. G. Solution of hydrogen in niobium. Trans. Faraday Soc. 1969, 65, 2758-2765.

(76) Craft, A.; Kuji, T.; Flanagan, T. B. Thermodynamics, isotope effects and hysteresis for the triple-point transition in the niobium-hydrogen system. J. Phys. F: Met. Phys. 1988, 18, 1149 .

(77) Sieverts, A.; Gotta, A. Über die Eigenschaften einiger Metallwasserstoffe. Z. Anorg. Allg. Chem. 1928, 172, 1-31.

(78) Randzio, S.; Bojarski, K. Calorimetric measurements of heat of hydrogen desorption from nonstoichiometric chromium hydrides. Rocz. Chem. 1974, 48, 1375-1378.

(79) Baranowski, B.; Bojarski, K. Free-energy of formation of chromium hydride. Rocz. Chem. 1972, 46, 1403-1409.

(80) Tkacz, M.; Baranowski, B. Heats of formation and decomposition of nickel and $\mathrm{Ni}_{0.8} \mathrm{Cu}_{0.2}$ hydrides measured in high pressures of gaseous hydrogen. J. Less-Common Met. 1985, 113, 83-87.

(81) Baranowski, B.; Czarnota, I. The enthalpy of desorption for nickel hydride. Naturwissenschaften 1964, 51, 262-262.

(82) Tkacz, M. Enthalpies of formation and decomposition of nickel hydride and nickel deuteride derived from (p,c,T) relationships. J. Chem. Thermodyn. 2001, 33, 891897.

(83) Czarnota, I.; Baranowski, B. Enthalpy of formation of nickel hydride and deuteride. Bull. Acad. Pol. Sci., Ser. Sci. Chim. 1966, 14, 191-196.

(84) Antonov, V. E.; Belash, I. T.; Poniatovskii, E. G. T-P phase-diagrams of systems $\mathrm{Ni}-\mathrm{D}$ and $\mathrm{Ni}-\mathrm{H}$ at temperatures up to $375^{\circ}$ and pressures up to $20 \mathrm{kbars}$. Dokl. Akad. Nauk SSSR 1977, 233, 1114-1117. 
(85) Flanagan, T. B.; Luo, W.; Clewley, J. Calorimetric enthalpies of absorption and desorption of protium and deuterium by palladium. J. Less-Common Met. 1991, 172, $42-55$.

(86) Wicke, E.; Nernst, G. H. Zustandsdiagramm und thermodynamisches Verhalten der Systeme $\mathrm{Pd} / \mathrm{H}_{2}$ und Pd/D 2 bei normalen Temperaturen; H/D-Trenneffekte. Ber. Bunsen Ges. Phys. Chem. 1964, 68, 224-235.

(87) Clewley, J. D.; Curran, T.; Flanagan, T. B.; Oates, W. A. Thermodynamic properties of hydrogen and deuterium dissolved in palladium at low concentrations over a wide temperature range. J. Chem. Soc., Faraday Trans. 1 1973, 69, 449-458.

(88) Lässer, R.; Klatt, K. H. Solubility of hydrogen isotopes in palladium. Phys. Rev. B 1983, 28, 748-758.

(89) Burtovyy, R.; Utzig, E.; Tkacz, M. Studies of the thermal decomposition of copper hydride. Thermochim. Acta 2000, 363, 157-163.

(90) Hexagonal to cubic phase transition in $\mathrm{YH}_{3}$ under high pressure. Solid State Commun. 2005, 133, 477-480.

(91) Tkacz, M.; Palasyuk, T. Pressure induced phase transformation of $\mathrm{REH}_{3}$. J. Alloys Compd. 2007, 446-447, 593-597, Proceedings of the International Symposium on Metal-Hydrogen Systems, Fundamentals and Applications (MH2006).

(92) Antonov, V. E.; Bashkin, I. O.; Fedotov, V. K.; Khasanov, S. S.; Hansen, T.; Ivanov, A. S.; Kolesnikov, A. I.; Natkaniec, I. Crystal structure and lattice dynamics of high-pressure scandium trihydride. Phys. Rev. B 2006, 73, 054107-1-054107-6.

(93) Sidhu, S. S.; Heaton, L.; Zauberis, D. D. Neutron diffraction studies of hafniumhydrogen and titanium-hydrogen systems. Acta Crystallogr. 1956, 9, 607-614. 
(94) Niedźwiedź, K.; Nowak, B.; Zogał, O. J. ${ }^{91} \mathrm{Zr}$ NMR in non-stoichiometric zirconium hydrides, $\mathrm{ZrH}_{x}(1.55 \leq x \leq 2)$. J. Alloys Compd. 1993, 194, 47-51.

(95) Numakura, H.; Koiwa, M. Hydride precipitation in titanium. Acta Metall. 1984, 32, 1799-1807.

(96) Sidhu, S.; Murthy, N.; Campos, F.; Zauberis, D. Neutron and X-ray diffraction studies of nonstoichiometric metal hydrides. Advan. Chem. Ser. 1963, Vol: No. 39, 87-98.

(97) Asano, H.; Uematsu, S.; Fukiura, T. Detection of superlattice reflections from $\mathrm{Ta}_{2} \mathrm{H}$ by X-Ray powder diffraction. Trans. Jpn. Inst. Met. 1983, 24, 661-664.

(98) Schober, T.; Pick, M. A.; Wenzl, H. Electron microscopy of $\beta$-hydride in niobium. Phys. Status Solidi A 1973, 18, 175-182.

(99) Antonov, V.; Latynin, A.; Tkacz, M. T-P phase diagrams and isotope effects in the Mo-H/D systems. J. Phys.: Condens. Matter 2004, 16, 8387-8398.

(100) Antonov, V. Phase transformations, crystal and magnetic structures of high-pressure hydrides of $d$-metals. J. Alloys Compd. 2002, 330, 110-116, Proceedings of the International Symposium on Metal-Hydrogen Systems, Fundamentals and Applications (MH2000).

(101) Antonov, V.; Antonova, T.; Fedotov, V.; Hansen, T.; Kolesnikov, A.; Ivanov, A. Neutron scattering studies of $\gamma$-CoH. J. Alloys Compd. 2005, 73-76.

(102) Venkatraman, M.; Neumann, J. The Cr-H (chromium-hydrogen) system. J. Phase Equilib. 1991, 12, 672-677.

(103) Shilstein, S. S.; Glazkov, V.; Irodova, A.; Somenkov, V.; Antonov, V.; Ponyatovskii, E. The crystal structure of high-pressure hydrides. Z. Phys. Chem. 1985, 146, 129-135.

(104) Kuzovnikov, M. A.; Tkacz, M. Synthesis of ruthenium hydride. Phys. Rev. B 2016, 93, 064103-1-064103-5. 
(105) Li, B.; Ding, Y.; Kim, D. Y.; Ahuja, R.; Zou, G.; Mao, H.-K. Rhodium dihydride $\left(\mathrm{RhH}_{2}\right)$ with high volumetric hydrogen density. Proc. Natl. Acad. Sci. U. S. A. 2011, $108,18618-18621$.

(106) Glazkov, V.; Irodova, A.; Somenkov, V.; Shilshtein, S. S.; Antonov, V.; Ponyatovskii, E. Neutron diffraction study of the structure of technetium hydrides. Fiz. Tverd. Tela 1984, 26, 3261-3265.

(107) Antonov, V.; Belash, I.; Degtyareva, V.; Mogilyansky, D.; Ponomarev, B.; Shekhtman, V. Crystal structure and magnetic properties of high-pressure phases in the Fe-H and Fe-Cr-H systems. Int. J. Hydrogen Energy 1989, 14, 371-377.

(108) Yamakata, M.; Yagi, T.; Utsumi, W.; Fukai, Y. In situ X-ray observation of iron hydride under high pressure and high temperature. Proc. Jpn. Acad., Ser. B 1992, $68,172-176$.

(109) Scheler, T.; Degtyareva, O.; Marqués, M.; Guillaume, C. L.; Proctor, J. E.; Evans, S.; Gregoryanz, E. Synthesis and properties of platinum hydride. Phys. Rev. B 2011, 83, $1-5$.

(110) Luo, S.; Flanagan, T. B. Supersaturation and hydride formation in the dilute phase of $\mathrm{Pd}-\mathrm{H}$ and $\mathrm{Pd}-\mathrm{Mn}-\mathrm{H}$ alloys. J. Alloys Compd. 2006, 419, $110-117$.

(111) Goedkoop, J.; Andresen, A. The crystal structure of copper hydride. Acta Crystallogr. 1955, 8, 118-119.

(112) Tkacz, M.; Burtovyy, R. Decomposition of the hexagonal copper hydride at high pressure. Solid State Commun. 2004, 132, 37-41.

(113) Wiberg, E.; Henle, W.; Bauer, R. Notizen: Zur Kenntnis eines Zinkwasserstoffs $\mathrm{ZnH}_{2}$. Z. Naturforsch., B: J. Chem. Sci. 1951, 6, 393-393. 
(114) Beavis, L. C. Characteristics of some binary transition metal hydrides. J. LessCommon Met. 1969, 19, 315-328.

(115) Antonov, V.; Cornell, K.; Fedotov, V.; Kolesnikov, A.; Ponyatovskii, E.; Shiryaev, V.; Wipf, H. Neutron diffraction investigation of the dhcp and hcp iron hydrides and deuterides. J. Alloys Compd. 1998, 264, 214-222.

(116) Liu, Y.; Duan, D.; Tian, F.; Wang, C.; Ma, Y.; Li, D.; Huang, X.; Liu, B.; Cui, T. Stability and properties of the $\mathrm{Ru}-\mathrm{H}$ system at high pressure. Phys. Chem. Chem. Phys. 2016, 18, 1516-1520.

(117) Ross, D.; McKergow, M.; Witchell, D.; Kjems, J. Neutron diffraction studies of domain growth associated with the $50 \mathrm{~K}$ anomaly in $\mathrm{Pd}-\mathrm{D}$. J. Less-Common Met. 1991, 172, $169-182$.

(118) Oganov, A. R.; Glass, C. W. Crystal structure prediction using ab initio evolutionary techniques: Principles and applications. J. Chem. Phys. 2006, 124, 244704-1-24470415.

(119) Meredig, B.; Agrawal, A.; Kirklin, S.; Saal, J. E.; Doak, J. W.; Thompson, A.; Zhang, K.; Choudhary, A.; Wolverton, C. Combinatorial screening for new materials in unconstrained composition space with machine learning. Phys. Rev. B 2014, 89, 094104-1-094104-7.

(120) Liu, Z.-K. First-principles calculations and CALPHAD modeling of thermodynamics. J. Phase Equilib. Diffus. 2009, 30, 517-534. 


\section{Graphical TOC Entry}

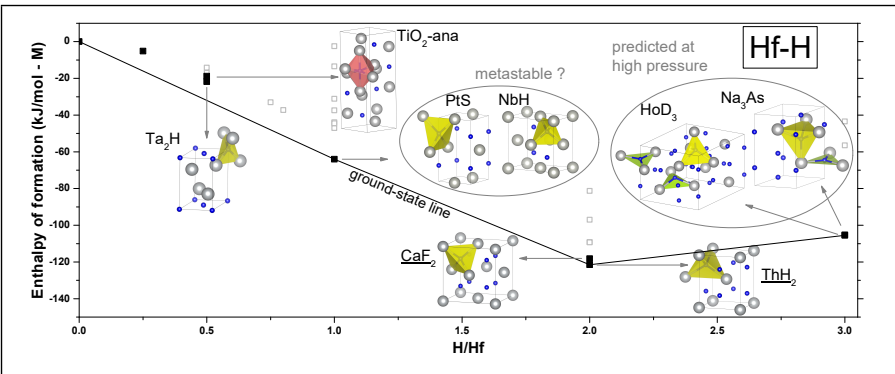

High-throughput DFT and phonon calculations were systematically performed for 31 binary metal-hydrogen systems distributed for a set of 30 potential crystal structures. The calculated enthalpies of formation were represented as functions of $\mathrm{H}$ composition, $y$. The sequence of stable hydrides $M \mathrm{H}_{y}$ (ground-state) given by the convex hull was found in agreement with the experimental observations. Besides, predictions could be made on metastable and high pressure hydrides, providing orientations for new materials synthesis. 